\title{
Responsabilidad social de empresas de ecoturismo, normativa y política pública en ciudad de México
}

\section{Social responsibility of ecotourism, normative and public policy companies in Mexico city}

DOI: https://doi.org/10.17981/juridcuc.15.1.2019.14

Fecha de Recepción: 04/08/2019. Fecha de Aceptación: 07/10/2019

\author{
Bertha Palomino Villavicencio \\ Instituto Politécnico Nacional (México) \\ berthapal@ipn.mx \\ Gustavo López Pardo \\ Universidad Nacional Autónoma de México (México) \\ lpardo@unam.mx
}

Para citar este artículo:

Palomino, B. y López, G. (2019). Responsabilidad social de empresas de ecoturismo, normativa y política pública en ciudad de México. JURÍDICAS CUC, 15(1). 353-382. DOI: http://dx.doi. org/10.17981/juridcuc.15.1.2019.14

Resumen

Esta investigación cualitativa tuvo como objetivo identificar las prácticas de Responsabilidad Social Empresarial (RSE) desarrolladaspor tres empresas de ecoturismo localizadas en el Suelo de Conservación de la Ciudad de México y su relación con la política pública local. A partir de cuatro ejes: calidad de vida en la empresa; compromiso con la comunidad; cuidado y preservación del medio ambiente y competitividad y relación con sus involucrados, se identificaron sus fortalezas, su desempeño ambiental y su relación con la comunidad, y sus debilidades en competitividad y relación con otros involucrados, así como calidad de vida en el trabajo. Este desempeño en materia de responsabilidad social contribuye a la sustentabilidad en sus dimensiones económica, ecológica y social de los emprendimientos estudiados y sus entornos, y tiene una gran correspondencia con los objetivos de los instrumentos de política pública y normatividad, tanto ambiental como social, en los que se puede soportar.

Palabras clave: ecoturismo; política pública; responsabilidad social empresarial; suelo de conservación; sustentabilidad
Abstract

This qualitative research aimed to identify the Corporate Social Responsibility (CSR) practices developed by three ecotourism companies located on the Conservation Soil of Mexico City and their relationship with local public policy. Based on four axes: quality of life in the company; commitment to the community; care and preservation of the environment and competitiveness and relationship with its stakeholders, its strengths, its environmental performance and its relationship with the community, and its weaknesses in competitiveness and relationship with others involved, as well as quality of life at work were identified. This social responsibility performance contributes to the economic, ecological and social sustainability of the enterprises studied and their surroundings, and has a great correspondence with the objectives of the public policy instruments and regulations, both environmental and social, in which it can be supported.

Keywords: ecotourism; public policy; corporate social responsibility; conservation soil; sustainability 


\section{INTRODUCCIÓN}

En la Ciudad de México (CDMX), anteriormente Distrito Federal (DF), desde finales de la década de los años 90 se han impulsado iniciativas para el desarrollo de actividades de ecoturismo, como una forma de conservación de los recursos naturales y la biodiversidad existentes en más de la mitad del territorio que conforma el llamado Suelo de Conservación (SC), cuya presencia es de vital importancia para la ciudad dados los bienes y servicios ambientales que proporciona, el agua para consumo humano y las actividades productivas y flores y hortalizas; además de captación de agua y dióxido de carbono, hábitat de biodiversidad mundial y local endémica, barrera contra los vientos, así como espacio de recreación para los habitantes de la ciudad, entre otros (Palomino y López, 2015).

En este territorio se asienta población originaria y avecindada que vive y desarrolla sus actividades productivas tradicionales reguladas por una normatividad que pretende preservar los bienes y servicios ambientales que proporciona, a fin de mantener la viabilidad natural y social del macro sistema megalopolitano que aglutina la Ciudad de México. Sin embargo, este espacio también vive enormes presiones derivadas de los mismos procesos de crecimiento que le han dado su origen: particularmente las modificaciones en el uso del suelo, por la expansión de la demanda inmobiliaria privada, crecimiento natural de las colonias y pueblos tradicionales y el incremento de la necesidad de vivienda popular. Estas presiones sobre el suelo de conservación se ven incrementadas por la ampliación de la frontera agrícola, la tala clandestina de madera, la extracción de tierra, flora y fauna, las quemas agrícolas y los incendios forestales (Castellanos, García y Cano, 2017) (Palomino y López, 2015).

En este escenario, el desarrollo de las actividades de ecoturismo, que desde los gobiernos de la ciudad se han impulsado, tienen como objetivo diversificar la producción rural, generar nuevos empleos, ingresos y contribuir así a mejorar las condi- 
ciones de vida de la población ahí residente, pero también como instrumento de la conservación ecosistémica y mecanismo para contener el avance de la mancha urbana. La importancia de estos proyectos también radica en enriquecer la oferta de recreación y esparcimiento para una población de casi 18 millones de habitantes de la Ciudad de México y la zona metropolitana del Estado de México.

\section{Marco legal para el turismo alternativo en la CDMX}

El soporte legal y normativo de experiencias productivas de turismo alternativo en su modalidad ecoturística en el SC tiene dos vertientes de política pública: la ambiental y la social.

En cuanto a la política ambiental, destaca el Programa General de Ordenamiento Ecológico del Distrito Federal ${ }^{1}$ 2000-2013, en la Ley Ambiental del Distrito Federal (Estados Unidos MexicanosEUM. Gobierno del Distrito Federal, 2000) que define legamente al Suelo de Conservación en la Ciudad de México. Este programa rector aún vigente "fomentará y fortalecerá el adecuado uso del territorio, la conservación y manejo sustentable de los recursos naturales, y orientará el desarrollo de las actividades productivas hacia zonas con capacidad adecuada" (EUM. Gobierno del Distrito Federal, 2000, p. 13), proporciona el carácter conservacionista del espacio en el que se desarrollan las actividades turísticas objeto de estudio de esta investigación.

Ahora bien, el soporte legal de carácter social específico para las empresas ecoturísticas actuales es el Programa de Turismo Alternativo y Patrimonial creado desde el año 2012, de la Secretaria de Desarrollo Rural y Equidad para las Comunidades (EUM. Gobierno de la CDMX, 2018), aunque existen empresas de ecoturismo que operan hace más de 20 años en esta zona.

\footnotetext{
${ }^{1}$ A partir de una reforma de la Constitución Política de los Estados Unidos Mexicanos del 29 de enero del 2016 cambió el nombre de la capital del país de Distrito Federal a Ciudad de México y se constituyó en la entidad federativa 32 de la nación (EUM. Congreso de la Unión, 2016).
} 
El programa contribuye a garantizar los derechos económicos, sociales y culturales de las personas de pueblos originarios a partir de iniciativas con enfoque turístico que propicien la creación de opciones de empleo en el sector rural para evitar el abandono o venta de tierra y el mejoramiento de la economía de las y los prestadores de servicios turísticos y personas emprendedoras del turismo alternativo (EUM. Gobierno de la CDMX, 2018).

Lo anterior es explicable porque las empresas de ecoturismo que se han desarrollado en el SC, suelo rural, son en su mayoría, sociales, con miembros indígenas y con un fuerte arraigo local, por lo cual responden como principio básico a la búsqueda del bien común de la comunidad que se antepone a la racionalidad económica hegemónica bajo la que actúan las empresas privadas en la sociedad de mercado.

Es en este marco en el que se investigó la presencia de la llamada Responsabilidad Social Empresarial (RSE) como uno de los caminos de las organizaciones económicas para avanzar en la construcción de la sustentabilidad en sus dimensiones ecológica, social y económica, en tres de las empresas más destacadas y posicionadas en el mercado del ecoturismo en la Ciudad de México. Así como sus manifestaciones, y sus alcances, con la finalidad de ilustrar un fenómeno que aún no se visibiliza con nitidez y que hace referencia a uno de los rasgos más importantes de las empresas sociales: su contribución al mejoramiento de la calidad de vida de sus participantes y de la comunidad en la que se asienta, así como a la conservación del gran ecosistema de la capital del país.

\section{Desarrollo}

A partir de la llamada crisis ambiental no solo se incrementó la búsqueda de formas de organización productivas más acordes con el entorno natural y el desarrollo sustentable, sino que también se puso atención y se incrementaron las prácticas sociales responsables. La búsqueda del desarrollo sustentable también significó un cuestionamiento a la función de la organización em- 
presarial centrada exclusivamente en el interés económico de los accionistas ${ }^{2}$ (Lozano, 2011) y propició un cambio en el paradigma hegemónico organizacional, incorporando el compromiso ético y social a su funcionamiento y gestión. Si bien la llamada Responsabilidad Social Empresarial en un primer momento hizo referencia a los impactos que las acciones de la empresa tenían en el entorno natural, paulatinamente incorporó otros aspectos sociales y económicos vinculados con su gestión organizacional (Burrel y Morgan, 1979).

Pero las crisis económicas de las últimas décadas y el incremento de las desigualdades sociales también han motivado que cada vez más y desde distintos ámbitos, se demande un comportamiento más ético en las actividades productivas, como parte de esta tendencia mundial de buscar modelos de desarrollo que modifique la perspectiva actual.

Este "nuevo" compromiso ético de las empresas también ha sido explicado, justificado y alentado por distintas teorías económicas que si bien emanan del siglo XVIII han venido adquirido nueva vitalidad, sobre todo por los resultados deficitarios que ha venido presentando el modelo neoliberal, en donde el grueso de la población se ve enfrentada a los embates de la crisis económica; la profunda desigual económica y la incapacidad del mercado para resolver los problemas estructurales de nuestras economías (Organización de las Naciones Unidas-ONU, 2015).

\footnotetext{
${ }^{2}$ Lejos de lo que señala la economía clásica y lo expuesto por Friedman en forma contundente al afirmar que la responsabilidad básica y razón de ser de la empresa, es la obtención de los mayores rendimientos económicos para los propietarios o accionistas, generando con ello beneficios a la sociedad mediante la contribución de impuestos, el cumplimiento de las normas y la generación de empleo (Friedman, 1970), en los últimos años cada vez más sectores (incluidos los empresarios) señalan que las organizaciones empresariales tienen una responsabilidad más allá de la económica, tienen una responsabilidad ético-social con la sociedad (Lozano, 2011).
} 
La economía social ${ }^{3}$, la economía solidaria ${ }^{4}$ y la economía civil ${ }^{5}$ explican el comportamiento ético de las empresas desde una perspectiva teórica que si bien contempla al mercado, lo hace a partir de los principios de reciprocidad y de fraternidad, donde el centro de las relaciones económicas es el bien común. Estas consideran que en la actividad económica y en el mercado hay lugar para otros principios que no sean los de la ganancia y el mero intercambio utilitario, por lo que promueven un nuevo modelo económico que considera el interés general, la importancia de la comunidad y persigue el bien de la sociedad en general.

Estas teorías encuadran las experiencias económicas alternativas que a nivel mundial se han venido construyendo por individuos, familias, colectivos, grupos y comunidades (Ávila, 2015), como opción para decidir propiamente su futuro, creando fuentes de empleo apegadas a obtener un desarrollo y un estado de bienestar grupal, preservando los recursos naturales (Alvarado, Moreno y Silva, 2017), y fomentar el restablecimiento del tejido social, mediante una convivencia basada en principios (igualdad, fraternidad, bien común) civiles, sociales y solidarios (Guridi y Pérez, 2014).

${ }^{3}$ La economía social reúne en su cuerpo teórico conceptos e ideas con origen en Latinoamérica y Europa (Pérez, 2014; Guerra, 2013; 2011; 2010; Da Ros, 2007) y se refiere a un conjunto heterogéneo de prácticas manifestadas en todas las esferas del proceso económico que buscan garantizar la seguridad de los medios de vida de las personas y democratizar la economía (Coraggio, 2011; Laville y García, 2009).

${ }^{4}$ La economía solidaria hace referencia a un conjunto heterogéneo de enfoques teóricos, realidades socioeconómicas y prácticas empresariales que, frente a la lógica del capital, la mercantilización de las esferas públicas y privadas y la búsqueda de máximo beneficio, persiguen relaciones de producción, distribución, consumo y financiación basadas en la justicia, la cooperación, la reciprocidad y la ayuda mutua. La economía solidaria aboga por situar a las personas y su trabajo en el centro del sistema económico, otorgando a los mercados un papel instrumental al servicio del bienestar de todas las personas (Pérez, Etxezarreta y Guridi , 2009).

${ }^{5}$ La economía civil fue acuñada en el siglo XVIII por el economista y teólogo italiano Antonio Genovesi, y parte de la centralidad del hombre en la economía, el bien común y el principio de reciprocidad. En esta perspectiva el interés de los individuos se realiza junto al interés de los demás y no sin contar con los demás o en contra de los demás, por lo que el bien común presupone recuperar la racionalidad en la economía, dando protagonismo al principio de reciprocidad (Zamagni, 2014). 
Es en este contexto que la RSE ha sido objeto de atención desde hace largo tiempo por parte de los académicos y los directivos de las empresas. Según Epstein (2009) consiste en un conjunto complejo de dimensiones de la empresa, de carácter gradual, puesto que se presenta como un proceso a construir paso a paso, proporcional, ya que la expectativa de su ejercicio y aplicación tiene una relación directa con el tamaño de la empresa y su correspondiente poder o capacidad de influencia en el mercado.

En México, la RSE se originó como iniciativa filantrópica, pero en la década de los 90 varió partiendo de que la filantropía era insuficiente para promover avances sociales. Por ello, el Centro Mexicano para la Filantropía (CEMEFI) desde 1997 reconoce a la empresa socialmente responsable como aquella que además de ofrecer productos y servicios de calidad, genera utilidades y empleos, paga impuestos, y también reconoce los problemas que aquejan a su comunidad y propone alternativas para su solución (Abreu, 2009).

En este camino de formación de la conciencia social empresarial en el país, la globalización ha jugado una parte primordial al abrir a las empresas nacionales mecanismos de competencia inequitativos y demandas adicionales de responsabilidad social empresarial en sus productos o servicios, imponiendo demandas específicas de calidad e integración de sus estrategias de negocios, procesos, estándares de trabajo y cumplimientos de requisitos legales y éticos ante sus clientes extranjeros, gobiernos y competencia, al proyectar la interpretación de la responsabilidad social más allá de la visión nacional (De la Rosa, 2016, p. 222).

El sector empresarial, principalmente la Confederación patronal de la República Mexicana (Coparmex) ha sido en el país la mayor impulsora de la RSE; por su iniciativa se creó en el CEMEFI el distintivo Empresa Socialmente Responsable (ESR), cuyo objetivo es:

[...] promover y apoyar la adopción de los principios de la RSE como parte de la cultura y estrategia de negocios de las empresas, sustentando el cumplimiento de los estándares propuestos en la RSE, a fin de generar un factor más de competitividad empresarial con compromiso (De la Rosa, 2016, p. 24). 
Cabe mencionar que al igual de lo que ha sucedido con la interpretación y aplicación del desarrollo sustentable, la llamada responsabilidad social de las empresas se ha analizado desde diversos enfoques. Según Abreu (2009) y Licandro, Ramírez, Alvarado-García, Vega y Correa (2019), aunque no se ha logrado una definición de Responsabilidad Social Empresarial (RSE) comúnmente aceptada, ni existe un consenso en cuanto a sus objetivos y elementos; aunque de acuerdo con Correa, Flynn y Amit (2004) hay aspectos que deben ser considerados de manera prioritaria como: Ética empresarial, Calidad de Vida (al interior de las empresas), Vinculación y compromiso con la comunidad y sus desarrollo y cuidado y preservación del medio ambiente. Otros autores incorporan la Competitividad y relación con sus involucrados como parte de estos aspectos. Así, la dimensión integral de la Responsabilidad Social Empresarial (RSE) incorpora las siguientes categorías:

\section{Calidad de vida en la empresa}

Una empresa ofrece calidad de vida cuando opera éticamente y se interesa por el bienestar de sus integrantes; fomenta el ejercicio ético en todas sus operaciones (procesos, productos y/o servicios), así como la inclusión y diversidad en su fuerza laboral; cuenta con esquemas de desarrollo integral para sus trabajadores y familias; además de procurar el balance vida familiar-vida laboral al interior de la organización.

\section{Competitividad y relación con sus involucrados}

Una empresa se relaciona de una manera justa y solidaria con sus involucrados cuando, ante todo, cumple con todas sus obligaciones ante las autoridades, con sus accionistas o socios, construye relaciones de ganar-ganar con los diferentes involucrados en la cadena de valor, como por ejemplo, con sus proveedores y clientes, satisface a sus clientes y mantiene una relación respetuosa con sus competidores. 
Vinculación y compromiso con la comunidad y su desarrollo

Una ESR se empeña en mejorar su entorno inmediato y el de la comunidad con la cual se relaciona cuando realiza aportaciones y/o inversiones en beneficio de ella, realiza o participa en actividades sociales y comunitarias y promueve el trabajo voluntario de sus empleados hacia la comunidad.

\section{Cuidado y preservación del medioambiente}

Una ESR se compromete con el cuidado del medio ambiente si lo cuida y cumple con las obligaciones ambientales locales, si tiene políticas o programas para su cuidado, así como participa o apoya campañas de prevención, conservación y/o de su regeneración.

También y hasta ahora se consideraba a la RSE como “... la integración voluntaria, por parte de las empresas, de las preocupaciones sociales y medioambientales en sus operaciones comerciales y sus relaciones con sus interlocutores" (Unión Europea. Comisión de las Comunidades Europeas, 2001), por lo cual se dice que trasciende las responsabilidades jurídicas, preocupándose por la calidad de vida los diversos grupos de interés y las afectaciones que pueda causar al entorno.

Para Chirinos, Fernández y Sánchez (2013) "como consecuencia del grado de madurez que las empresas alcancen en materia de Responsabilidad Social se logra llegar al concepto de sustentabilidad empresarial" (p. 4), lo cual tiene que reforzarse en las estrategias se competitividad, convirtiéndose en esfuerzos sociales orientados a la preservación ecológica y al equilibrio entre lo económico, lo social y lo ambiental.

Así, "la sustentabilidad empresarial es un nuevo paradigma en la gestión de las empresas. Es una alternativa al modelo de crecimiento tradicional y de la maximización de la rentabilidad" (Wilson, 2003). Las empresas sustentables se caracterizan por la armonización y unión de los objetivos sociales y medioambientales, orientados de acuerdo a los intereses de los grupos de interés. 
Las nuevas orientaciones en la demanda internacional y nacional y los acontecimientos en el escenario social pugnan por el impulso de un enfoque sustentable en los negocios, buscando nuevos modelos alternativos para ejecutar las actividades económicas, una de éstas, el turismo.

\section{Metodología}

Para lograr el objetivo general de la investigación: Determinar la importancia de la Responsabilidad Social Empresarial (RSE) en negocios de ecoturismo de la Ciudad de México, como estrategia de sustentabilidad empresarial y su relación con el marco local de política pública, se realizaron tres etapas. La primera de ellas consistió en una investigación documental del suelo de conservación de la CDMX y de la política pública aplicable a nivel local. Se identificaron y analizaron dos instrumentos de política pública relacionados con el SC de la CDMX, el Programa General de Ordenamiento Ecológico del Distrito Federal de la SMA (DF, 2000) y el Programa de Turismo Alternativo y Patrimonial, operado por la SEDEREC (CDMX, 2018), por considerarlos vinculados con la Responsabilidad Social Empresarial investigada en el suelo rural de conservación

En la segunda etapa se seleccionaron de un universo de 13 negocios, las empresas ecoturísticas Parque ejidal San Nicolás Totolapan, Rescate ecoturístico Segundo Dinamo y Parque de ecoturismo y educación ambiental Los Laureles, como estudios de caso por su presencia y posicionamiento en el mercado de turismo alternativo local.

Posteriormente, en la tercera etapa, se realizó el diagnóstico de la RS de las empresas muestra considerando los cuatro ejes ya mencionados con anterioridad: Calidad de vida en la empresa, compromiso con la comunidad, cuidado y preservación del medio ambiente y competitividad y relación con sus involucrados. Para este fin se utilizaron dos instrumentos: una guía de observación para las visitas a las empresas y un instrumento adaptado de investigaciones previas en empresas de turismo alternativo (Palomino y 
López, 2011) (Palomino y López, 2015). Este consta de 60 ítems, con respuestas posibles en una escala de Likert, del 5 al 1, representando en este orden de la mayor a la menor coincidencia con el enunciado obtenido en de las entrevistas a los administradores de los tres negocios analizados, considerados como informantes de calidad. Con el procesamiento de la información en campo y la información de las entrevistas mencionadas, se evaluó el desempeño de las empresas en las categorías analizadas, detectando las fortalezas debilidades sobresalientes

En la cuarta y última etapa se analizó el desempeño de RSE de las empresas estudiadas a la luz de los dos instrumentos seleccionados como marco de política pública en esta investigación.

\section{Resultados}

\section{Parque Ejidal San Nicolás Totolapan}

Es la empresa ecoturística de mayor antigüedad en el SC, al operar desde 1998 y es un referente nacional e internacional como empresa que tiene en sus principios a la sustentabilidad integral, por la coherencia y congruencia de su actuar, así como su tenacidad, diversificación del producto turístico y permanencia exitosa en el mercado local de esta modalidad turística. El parque abarca una superficie de aproximadamente 1900 has, y se ubica en la alcaldía Magdalena Contreras, en el suroeste de la ciudad en la zona conocida como "Gran Bosque de Agua" por su significado estratégico como corredor biológico y zona de recarga del acuífero, además de ser hábitat de especies amenazadas o en peligro de extinción (Ávila, 2012) (Balam, 2007).

Esta cooperativa turística se constituyó como una opción productiva sustentable enmarcada en los instrumentos legales y normativos de la Ciudad de México para asegurar la posesión del territorio del pueblo originario náhuatl y ejido San Nicolás Totolapan, ante la enorme ocupación legal e ilegal de la mancha urbana sobre su superficie boscosa; la tala, la caza y la extracción de 
flora y fauna ilegales; pero sobre todo como respuesta al proyecto de concesión de su territorio por el gobierno local a empresas y organizaciones no gubernamentales nacionales e internacionales para desarrollar proyectos de conservación ecológica de la región del Ajusco medio ante la inminente realidad de deterioro ecológico.

De esta manera, el SNTL es una empresa ecoturística que busca la rentabilidad, la generación de ingresos y empleos, el uso sustentable de su territorio, así como el reconocimiento y respeto a su organización social ejidal, a su patrimonio cultural y al mejoramiento de las condiciones de vida de los habitantes del pueblo. Tiene una oferta de recreación y turística diversa turística, considerada como consolidada tanto por su planeación como por su ejecución.

TABLA 1

Características generales de las empresas ecoturísticas estudiadas

\begin{tabular}{|c|c|c|c|}
\hline $\begin{array}{c}\text { Características } \\
\text { de los } \\
\text { Proyectos }\end{array}$ & $\begin{array}{c}\text { Parque Ejidal } \\
\text { San Nicolas } \\
\text { Totolapan }\end{array}$ & $\begin{array}{c}\text { Parque de } \\
\text { Ecoturismo y } \\
\text { Educación Ambiental } \\
\text { Los Laureles }\end{array}$ & $\begin{array}{l}\text { Parque y } \\
\text { Corredor } \\
\text { Ecoturístico } \\
\text { Los Dinamo }\end{array}$ \\
\hline $\begin{array}{l}\text { Ecosistema Pre- } \\
\text { dominante }\end{array}$ & $\begin{array}{l}\text { Bosque de encino, } \\
\text { pino y oyamel }\end{array}$ & $\begin{array}{l}\text { Bosque oyamel, pino y } \\
\text { encino }\end{array}$ & $\begin{array}{l}\text { Bosque de oya- } \\
\text { mel, pino y en- } \\
\text { cino. Pastizales }\end{array}$ \\
\hline $\begin{array}{l}\text { Ubicación (alcal- } \\
\text { día) }\end{array}$ & $\begin{array}{l}\text { Magdalena Con- } \\
\text { treras }\end{array}$ & Cuajimalpa & Cuajimalpa \\
\hline $\begin{array}{l}\text { Conservación } \\
\text { inicial de los eco- } \\
\text { sistemas }\end{array}$ & Alto & Medio & Medio \\
\hline Superficie & 1900 ha & 120 ha & 2293 ha \\
\hline $\begin{array}{l}\text { Propiedad del } \\
\text { suelo }\end{array}$ & Ejidal & Comunal & Comunal \\
\hline $\begin{array}{l}\text { Iniciativa y/o pro- } \\
\text { piedad del pro- } \\
\text { yecto }\end{array}$ & Ejidal & Comunal & Comunal \\
\hline $\begin{array}{l}\text { Organización y } \\
\text { participación so- } \\
\text { cial }\end{array}$ & Alta & Alta & Alta \\
\hline Oferta ecoturístic & & & \\
\hline
\end{tabular}




\begin{tabular}{cccc}
\hline & & Parque de & Parque y \\
Características & Parque Ejidal & Ecoturismo y & Corredor \\
de los & San Nicolas & Educación Ambiental & Ecoturístico \\
Proyectos & Totolapan & Los Laureles & Los Dinamo \\
& & & \\
\hline
\end{tabular}

Alto

Comedor, cabañas, área de acampado, centro de educación ambiental, salón de usos múltiples, estaciona-

Nivel de planta miento, senderos turística para ciclismo de montaña, senderos interpretativos, criadero de trucha arcoíris, unidad de manejo ambiental de venado cola blanca. Vivero forestal.

Alto

Área de acampado, te-

Medio mascal, gocha, centro de educación ambiental, área de juegos infantiles, vivero educativo, capilla al aire libre, restaurantes, salón de eventos, estacionamiento y sanitarios

Palapas de venta de comida, escuela de educación ambiental, granjas de trucha, área de acampado.

Práctica de ciclismo de montaña,

Actividades y servicios senderismo, campismo, tirolesa, cabalgata, pesca deportiva y recreativa. Actividades de cultura forestal y educación ambiental.

Guías y vigilancia para la observación de flora y fauna. Estacionamiento, teléfono. Organización de eventos.

Senderismo, medicina tradicional observación de flora y fauna, agroturismo y talleres de educación ambiental. Organización de eventos
Alta
Alta
Media

Senderismo, escalada en roca, carrera en campo, ciclismo de montaña, campismo. Observación de flora y fauna, talleres de educación ambiental. Organización de eventos

Diversidad de actividades turísticas

Consolidación del proyecto Alta Alta

Alta 


\begin{tabular}{|c|c|c|c|}
\hline $\begin{array}{c}\text { Características } \\
\text { de los } \\
\text { Proyectos }\end{array}$ & $\begin{array}{l}\text { Parque Ejidal } \\
\text { San Nicolas } \\
\text { Totolapan }\end{array}$ & $\begin{array}{c}\text { Parque de } \\
\text { Ecoturismo y } \\
\text { Educación Ambiental } \\
\text { Los Laureles }\end{array}$ & $\begin{array}{l}\text { Parque y } \\
\text { Corredor } \\
\text { Ecoturístico } \\
\text { Los Dinamo }\end{array}$ \\
\hline \multirow{2}{*}{$\begin{array}{l}\text { Percepción } \\
\text { de impacto } \\
\text { económico local }\end{array}$} & Alto & Alto & Alto \\
\hline & $\begin{array}{l}20 \text { empleos fijos y } \\
30 \text { temporales. }\end{array}$ & $\begin{array}{l}37 \text { empleos fijos y } 17 \\
\text { empleos temporales. }\end{array}$ & $\begin{array}{l}12 \text { empleos per- } \\
\text { manentes y } 30 \\
\text { temporales }\end{array}$ \\
\hline $\begin{array}{l}\text { Percepción de } \\
\text { impacto social } \\
\text { (beneficio } \\
\text { población local) }\end{array}$ & Alto & Medio & Medio \\
\hline $\begin{array}{l}\text { Percepción de } \\
\text { Impacto en la } \\
\text { conservación eco- } \\
\text { sistémica }\end{array}$ & Alto & Medio & Medio \\
\hline $\begin{array}{l}\text { Impacto de } \\
\text { sensibilización } \\
\text { y educación } \\
\text { ambiental }\end{array}$ & Medio & Medio & Medio \\
\hline $\begin{array}{l}\text { Principales pro- } \\
\text { blemas ambien- } \\
\text { tales }\end{array}$ & $\begin{array}{l}\text { Tala clandestina } \\
\text { Erosión y compac- } \\
\text { tación del suelo }\end{array}$ & $\begin{array}{l}\text { Asentamientos irregu- } \\
\text { lares } \\
\text { Tala clandestina }\end{array}$ & $\begin{array}{l}\text { Generación de } \\
\text { basura } \\
\text { Disposición } \\
\text { inadecuada de } \\
\text { basura } \\
\text { Fauna nociva }\end{array}$ \\
\hline
\end{tabular}

Fuente: Modificado de Palomino y López, 2015.

\section{Parque y Corredor Ecoturístico Los Dinamos}

Se ubica en la comunidad originaria náhuatl La Magdalena Atlitic de la alcaldía La Magdalena Contreras. Se encuentra en el área natural protegida Cuenca del Río Magdalena, con una superficie de 2293 kilómetros de pinos y oyameles en las partes altas y en las partes bajas, bosque mixto y encinos. En esta ANP corre el Río Magdalena, el único río vivo en la Ciudad de México (CDMX), aún empleado como fuente de abastecimiento para consumo humano. 
La empresa se constituyó en el año 2000 con el objetivo fundamental de generación de empleos e ingresos económicos para las familias de los socios desarrollando actividades de recreación, turismo y comercio, así como para el resguardo forestal y del medio ambiente (Comisión de Recursos Naturales y Desarrollo RuralCorenader, 2010). El Parque ofrece tanto actividades de ecoturismo como la escalada, senderismo, ciclismo, educación ambiental y zona para acampar, entre otras, así como medicina tradicional, propia del turismo rural y gocha (Tabla 1).

Parque ecoturístico y de educación ambiental Rancho de los Laureles

Se localiza en la comunidad de San Mateo Tlaltenango de la alcaldía Cuajimalpa. Es una zona boscosa de oyamel y pino ayacahuite, dos árboles navideños mexicanos. Al igual que los otros estudios de caso, la actividad de esta empresa se inició hace 6 años mejorar las condiciones de vida de la población a través de una opción económica y evitar el impacto negativo de la presión urbana. Cuenta con instalaciones para realizar campismo, ciclismo de montaña, medicina tradicional, criaderos de trucha, vivero y venadario educativos, área de juegos infantiles, restaurantes de comida

\section{Desempeño de las empresas en RSE}

Como se observa en la Figura 1 en referencia a la Calidad de vida en el trabajo, el Parque Ejidal de San Nicolás Totolapan obtuvo el mayor valor en esta categoría que expresa las condiciones internas de la empresa que favorecen un ambiente respetuoso y estimulante para los empleados, además de una persistente búsqueda de una operación ética en todos sus procesos. Por su lado Rancho Los Laureles y Parque Los Dinamos con los valores obtenidos expresan mayores áreas de oportunidad para brindar bienestar a sus colaboradores 


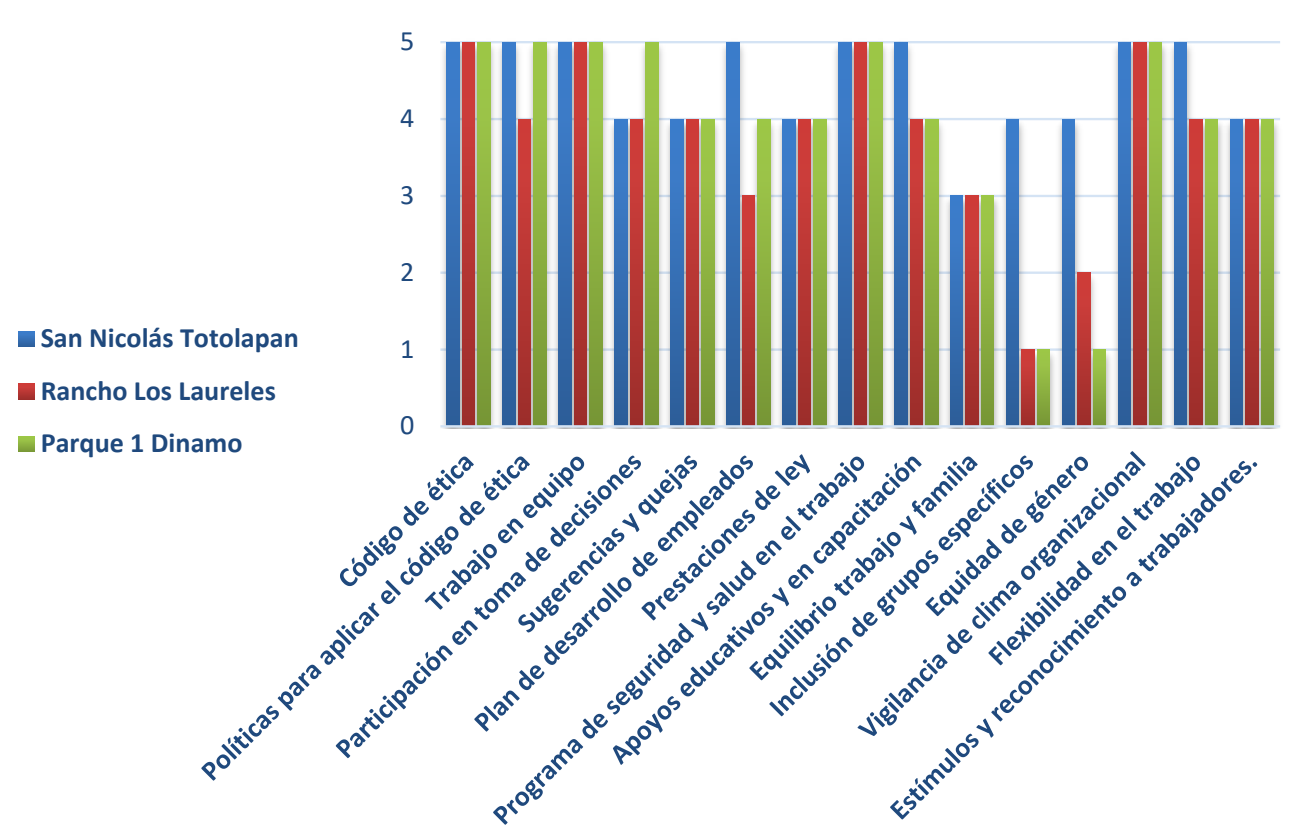

Figura 1. Calidad de vida en la empresa. Fuente. Elaboración propia.

Las fortalezas de las empresas en esta categoría correspondieron a la existencia y uso formal de un código de ética en la vida interna de las organizaciones, el fomento de trabajo en equipo, la participación en la toma de decisiones y el sentido de comunidad en sus colaboradores y la existencia de mecanismos para la comunicación entre directivos y trabajadores o colaboradores. El respeto a la dignidad de sus trabajadores y el cumplimiento de la normatividad laboral y de seguridad en el trabajo. Contar con planes de desarrollo de capacidades, actitudes y valores de sus colaboradores y sus familias a través de prestaciones superiores a la ley y apoyos educativos y de capacitación. La aplicación de prácticas laborales favorables al equilibrio entre trabajo y familia.

Mientras que las debilidades en esta categoría de las tres empresas son la aplicación de enfoque de equidad de género y con otros grupos minoritarios tanto para la contratación del personal como para la obtención de puestos directivos y la realización de vigilancia de clima organizacional para medir el nivel de satisfacción de sus trabajadores. 
En cuanto a Competitividad y relación con sus involucrados, como se observa en la Figura 2, la empresa que registró el mejor desempeño fue el Rancho ecoturístico Los Laureles, siguiendo en orden el Parque ejidal San Nicolás Totolapan y el Parque Los Dinamo. De tal suerte que las empresas cumplen con todas las obligaciones que las instancias gubernamentales imponen, buscando relaciones de justas, solidarias y de ganar-ganar con sus diversos involucrados.

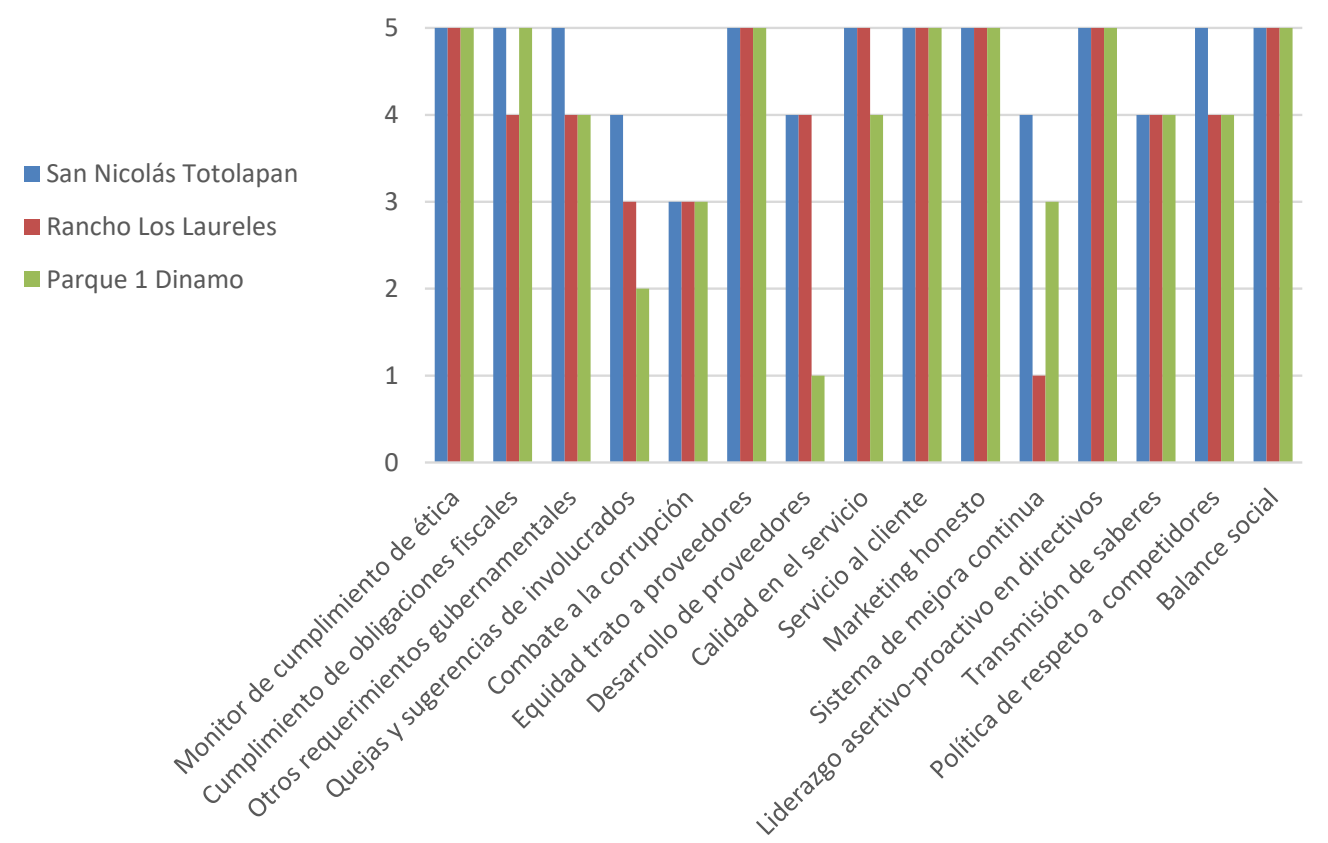

Figura 2. Competitividad y relación con sus involucrados.

Fuente. Elaboración propia.

Las fortalezas de las tres empresas en esta categoría correspondieron a contar con responsable de promover y monitorear su actuación ética, cumplimiento de obligaciones fiscales y atender a las solicitudes de diversas instancias gubernamentales; porque esto es un requisito para acceder a financiamientos y apoyos, tener con un esquema de mejoramiento continuo en aspectos como calidad y productividad, operar programas para desarrollar el liderazgo asertivo; desarrollar mecanismos para el intercambio de saberes de empleados de mayor experiencia a los de menor de menor experiencia. Además de la rendición periódica de cuentas de los logros y retos financieros, sociales y medioambientales (Balance Social). 
Estos aspectos corresponden a los usos y costumbres de la cotidianidad de pueblos originarios de la Cuenca de México que favorecen el bien común y la toma de decisiones colectivas.

Las debilidades reportadas consisten en la ausencia de programas de apoyo y cooperación para el desarrollo de sus proveedores, en particular de los locales, mecanismo formal para que sus diversos grupos de interés hagan llegar sugerencias, quejas o desacuerdos; política de equidad en selección y pago a sus proveedores, mecanismos que garanticen la congruencia entre calidad y precio más allá del mercado. Aunque cuentan con diversas certificaciones de calidad, en general no tienen un monitoreo permanente de ello, ni sistematizan sus resultados.

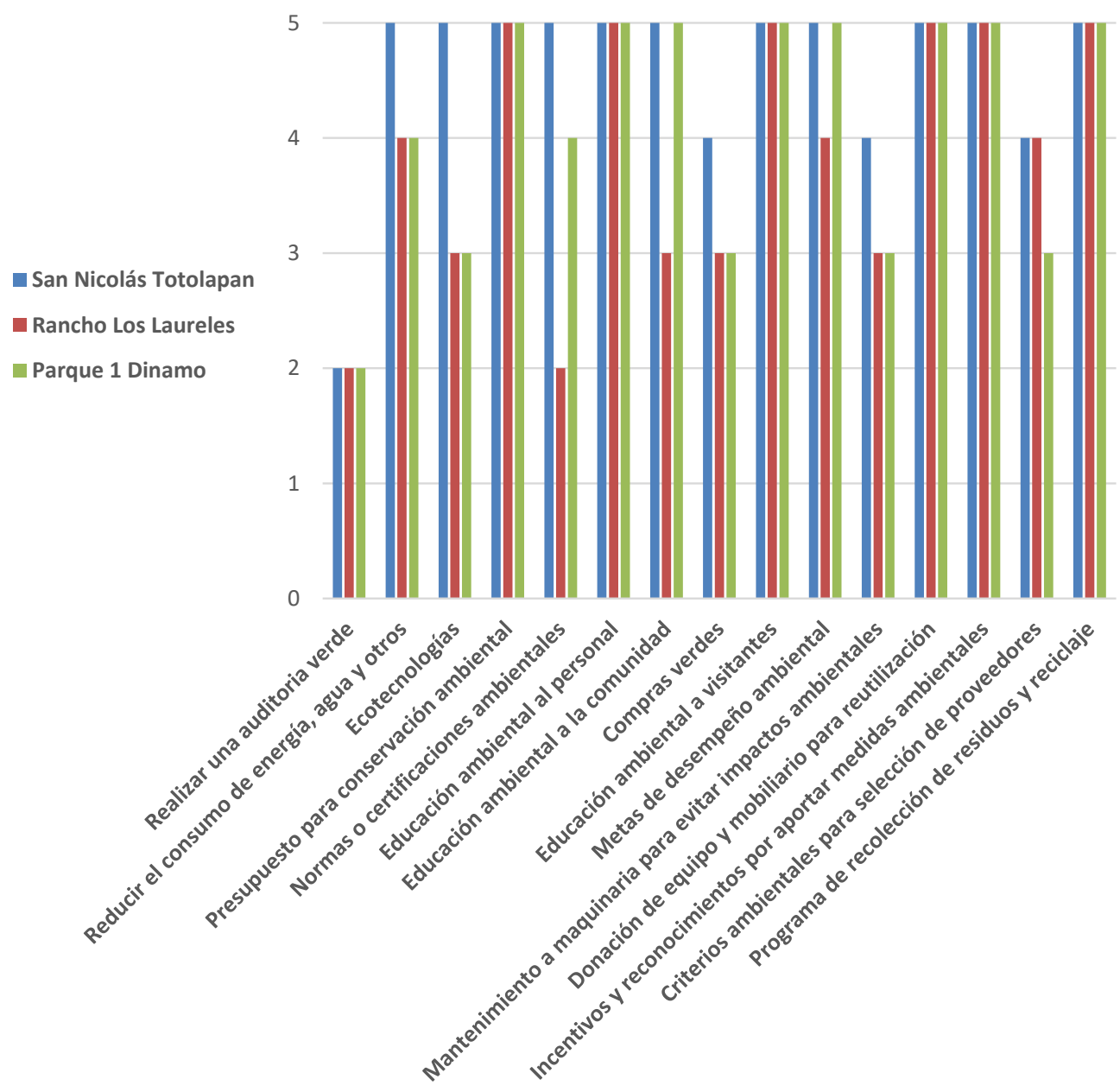

Figura 3. Cuidado y preservación del medio ambiente. Fuente. Elaboración propia. 
En la categoría de Cuidado y preservación del medio ambiente el Parque ejidal San Nicolás Totolapan tiene el mejor desempeño, posteriormente el Rancho Los Laureles y por último el Parque 1 Dinamo, desarrollando políticas y programas de cuidado del medio ambiente, uso de ecotecnias y educación ambiental (Figura 3).

Las fortalezas comunes a las empresas en esta categoría son: operar programas para aprovechar mejor los recursos y para minimizar la generación de desperdicios en las prácticas ecoturísticas, contar con sistemas o aparatos para disminuir las emisiones contaminantes, destinar una partida del presupuesto anual a programas de conservación o protección ambiental, aplicar alguna norma o certificación ambiental (ISO 9000, ISO 14000, Industria Limpia $\mathrm{u}$ otra). Todas las empresas tienen o se encuentran en proceso de certificación por desempeño ambiental tanto local como federal como el Distintivo "M" (EUM, 2017) y la NMX133 de ecoturismo (EUM, 2013). Además, establecen compromisos y metas para el cuidado ambiental, realizan acciones de concientización y educación de su personal, y la comunidad vecina para lograr estos. Adquieren algunos productos y materia prima reciclables. Realizan en mayor o menor medida acciones de educación ambiental con sus visitantes. Aunque las tres empresas reconocen realizarlo, los procedimientos o métodos con que llegan a sus clientes no permiten una sensibilización mayor de la importancia ambiental del suelo de conservación y de la particular labor de estas empresas en la conservación de sus patrimonios natural y cultural.

Debilidades, por ausencia o poca práctica empresarial de: políticas para reducir el consumo de energía eléctrica, agua, papel y productos tóxicos en sus oficinas e instalaciones; poco mantenimiento de sus equipos para la prevención de contaminación; generar incentivos y reconocimientos para los empleados que propongan y desarrollen procesos empresariales amigables con el ambiente; utilizar criterios ambientales para la selección de sus proveedores, insuficiente aplicación de los programas de recolección de residuos y reciclaje post-consumo. Además de que, aunque 
todas las empresas desarrollan acciones de educación ambiental con sus visitantes, estas tienen un énfasis en lo ecológico y no en el importante papel socio ambiental que juegan estos emprendimientos sociales como opciones productivas sustentables del suelo de conservación de la Ciudad México. Cabe mencionar que sus directivos consideran a la responsabilidad social empresarial sólo como una opción para grandes empresas y desconocen su enfoque pluralista, por lo cual tampoco han buscado su distintivo.
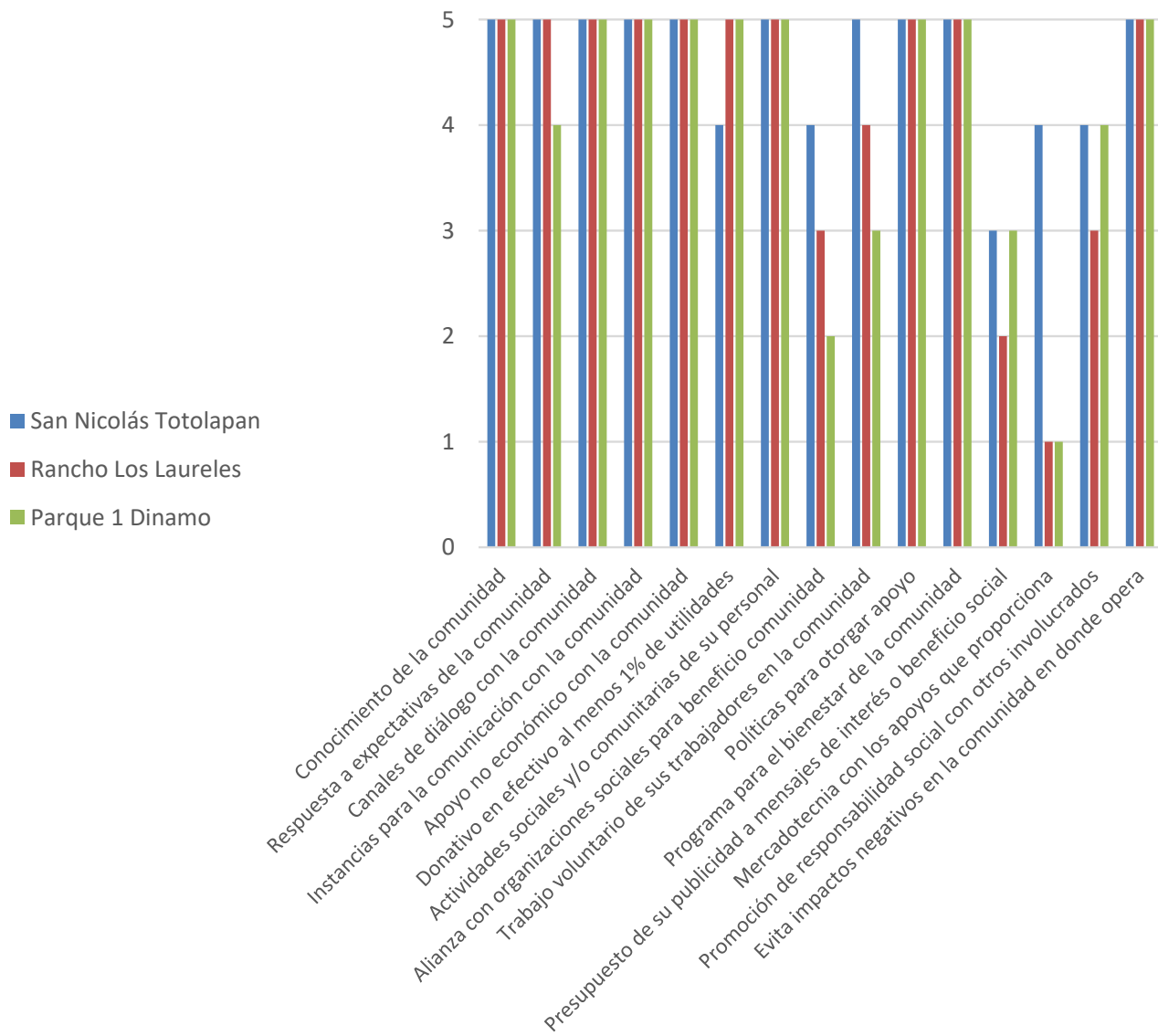

Figura 4. Vinculación y compromiso con la comunidad y su desarrollo. Fuente. Elaboración propia.

En la categoría de Vinculación y compromiso con la comunidad y su desarrollo el desempeño de las tres empresas alcanzó valores altos, destacando en primer lugar el Parque ejidal San Nicolás Totolapan, siguiendo en orden el Rancho Los Laureles y el Parque 1 Dinamos, en un rango muy pequeño. Lo anterior 
es explicable al ser empresas sociales con tradiciones, arraigo y sustento comunitario independientemente del tipo de propiedad, ejidal o comunal y buscan a priori el bienestar colectivo. Su base social son pueblos indígenas originarios de la Cuenca de México que tienen formas de organización y toma de decisión basadas en diversos grados de comunalidad, siempre primando la búsqueda del bien común.

Las fortalezas compartidas por las empresas en esta categoría son: Conocer las particularidades de la comunidad local e identificar sus expectativas y necesidades, responder a estas e impulsar su desarrollo, establecer canales de diálogo con la comunidad con la que se relaciona, contar con una instancia responsable del otorgamiento y seguimiento de sus donativos, apoyar con recursos no financieros a grupos organizados de la comunidad para la realización de actividades públicas, cívicas o de beneficio social, otorgar donativos en efectivo al menos el 1\% de sus utilidades para causas sociales, planear y realizar actividades sociales y/o comunitarias en las que involucra al personal y sus familias, mantener alianza con al menos alguna organización social para desarrollar un programa de apoyo a la comunidad y promover el trabajo voluntario de sus trabajadores hacia la comunidad. Todos estos aspectos forman parte de la naturaleza de empresas sociales comunitarias en donde la solidaridad tiene diversas expresiones para mejorar las condiciones de vida del pueblo al que pertenecen.

Sus debilidades consisten en la ausencia de políticas explícitas para los apoyos sociales que otorga la empresa; solo El Parque ejidal San Nicolás Totolapan, tiene definidas políticas y un programa formalizado para ello, ninguna destina parte de su presupuesto de su publicidad a mensajes con interés o utilidad social y tampoco promueven con acciones la participación y responsabilidad social entre sus proveedores, acreedores, clientes e instituciones con los que se relaciona. Hasta ahora las acciones de responsabilidad social identificadas sólo involucran a socios, trabajadores y comunidad a la que pertenece la empresa. 
A partir de estos resultados, la investigación documental y las entrevistas a los administradores se identificaron las oportunidades y las amenazas de estas empresas estudiadas para el desempeño como empresas socialmente responsables. Las oportunidades se refieren al interés del gobierno central de la CDMX (EUM. Secretaria del Medio Ambiente, 2014) y de los gobiernos delegacionales de fortalecer el segmento de turismo alternativo (EUM. Secretaria del Medio Ambiente, 2017), en especial del ecoturismo en el suelo de conservación para diversificar la oferta actual en esta actividad, además de contribuir al mejoramiento de las condiciones de vida de los pueblos originarios asentados en él. Esto a partir de mayor difusión, promoción y financiamiento concreto para el desarrollo de procesos no dañinos con el entorno y como medio para conservar las fuentes proveedoras de bienes y servicios ambientales a toda la región del Valle de México y la cultura de las poblaciones propietarias y poseedoras de esta región. Además de que estadísticas mundiales y nacionales reportan que el segmento de turismo que más se incrementa anualmente es el del turismo alternativo, en especial el ecoturismo, en un promedio de $10 \%$, debido a que grupos importantes de población buscan nuevas experiencias de recreación y turismo (World Tourism OrganizationUNWTO, 2014).

Las principales amenazas identificadas en esta investigación son la tendencia a la homogenización de oferta turística de estas empresas y del mercado en el Suelo de Conservación que está dirigido a una mayor comercialización de los espacios y servicios ofrecidos, pero no siempre bajo criterios de cuidado al ambiente, a la comunidad ni a la calidad de vida de los involucrados, basándose exclusivamente en un aumento temporal y coyuntural de la competitividad empresarial. Otro factor innegable es la constante presión del avance de la mancha urbana y las modalidades de actos ilegales como la tala clandestina, la extracción de tierra y especies de biodiversidad, así como el incremento de la inseguridad en parajes del suelo de conservación, como reflejo de un fenómeno generalizado en el país. 


\section{Conclusiones}

Aunque las empresas analizadas no se presentan como Empresas Socialmente Responsables muchos de los indicadores que convencionalmente se usan para definir estas prácticas empresariales e incluso para obtener alguno de sus distintivos, se encuentran en las gestiones cotidianas de estas organizaciones empresariales. Ello obedece a que sus objetivos, estructura y funcionamiento están ligados al mejoramiento de las condiciones de existencia de sus comunidades, a que sus tradiciones organizativas comunitaria o ejidales favorece el establecimiento de relaciones internas participativas y de constante información y rendición de cuentas (asambleas ejidales o comunales). Además, como su origen está en el marco de la conservación de los ecosistemas de la Cuenca de México, específicamente del SC de la Ciudad de México, desarrollan prácticas ambientales, en distinto grado o intensidad, que favorecen un aprovechamiento amigable con el ambiente.

Estas empresas tienen funcionamiento y actuación muy cercanas a las que presentan las empresas socialmente responsables, hasta ahora no con una finalidad de mejorar su imagen ante el público consumidor o incrementar su competitividad en el mercado actual, sino como expresión de su esencia en tanto organizaciones empresariales propias de las alternativas económicas que las comunidades locales están construyendo en contraposición de la economía privada, además de jugar un papel fundamental en impedir el avance de la mancha urbana al desarrollar un uso productivo de las zonas boscosas permitido en el Plan de Ordenamiento Ecológico de la región.

La difusión del desempeño en RSE de las empresas ecoturísticas analizadas en sus canales de promoción actuales y en otros de carácter empresarial, podría mejorar su posicionamiento en el mercado ecoturístico en México y a nivel internacional.

Sin duda, el desarrollo y desempeño en materia de responsabilidad social empresarial de las tres empresas ecoturísticas estudiados son acordes con el marco normativo, tanto de política ambiental 
como de la política social de la CDMX y con sus objetivos y principales estrategias. La correspondencia entre la responsabilidad social empresarial y la búsqueda de la sustentabilidad tanto el en POET como en el Programa de Turismo Alternativo y Patrimonial se entrelazan y corresponden, aunque en ninguna de los instrumentos de política pública referidos se mencione en forma explícita a la RSE.

De tal suerte, que en el POET se pretende la conservación y uso sustentable del SC considerando los límites del capital natural y la conservación de los bienes y servicios ambientales para la gran ciudad capital; así como en el Programa de Turismo alternativo y patrimonial se especifica que impulsa el desarrollo del turismo en el SC de la CDMX, como una actividad económica que diversifique las oportunidades y mejore las condiciones de vida de los pueblos originarios propietarios y poseedores de este territorio, bajo el respeto a sus derechos y patrimonios tanto natural como cultural. Lo anterior a su vez, tiene una correspondencia con las categorías de RSE en materia de calidad de vida de los participantes en la organización empresarial, con la vinculación y compromiso con la comunidad en la que se desarrolla, así como con el cuidado del medio ambiente, que son las principales fortalezas encontradas en las empresas investigadas. Las tareas pendientes de la RSE, mencionadas también en el Programa de Turismo alternativo y patrimonial son un mayor impulso a la competitividad empresarial y a extender las estrategias de RSE a toda la cadena de valor y sus involucrados.

Es conveniente destacar que los dos instrumentos de política pública que más inciden en el SC son por un lado, el de orientación ambiental por la importancia estratégica de este territorio por los bienes y servicios ambientales que provee a nivel local y regional; y por otro lado un instrumento de política de desarrollo social que promueve y regula la actividad económica del turismo en comunidades originarias del suelo rural de la CDMX, seguramente para mejorar las condiciones de vida de estas poblaciones. Esto ante la ausencia de una intervención pública en materia de desarrollo 
económico y en particular del sector turístico, orientaciones que serían conveniente incorporar para promover el desarrollo de productos turísticos para su comercialización en los mejores términos de competitividad y rentabilidad.

Por último, cabe marcar que la Responsabilidad social empresarial representa una oportunidad de reconocimiento, en una primera instancia por las mismas empresas ecoturísticas estudiadas, y después por los habitantes y visitantes de la Ciudad de México, de su papel protagónico en la construcción de opciones productivas sustentables, en la conservación de bienes y servicios ambientales de impacto nacional e internacional, de expresiones culturales originarias, así como a la diversificación de opciones de recreación y turismo.

\section{REFERENCIAS}

Abreu, J. L. (2009). Situación Actual de la RSE en el sector turístico mexicano, Daena. International Journal of Good Conscience, 4(2), 160-173.

Alvarado, L., Moreno, Z. y Silva, J. (2017). Políticas públicas para las pequeñas y medianas empresas del sector turismo: Perspectivas de análisis en su implementación. Revista Espacios, 38(61), 1-14.

Ávila, A. (2015). Análisis del Turismo alternativo en comunidades indígenas de Chiapas, México. Études caribéennes, Online, 31-32. https://doi.org/10.4000/etudescaribeennes.7601 Ávila. V. (2012). Diversificación productiva en el suelo de conservación de la Ciudad de México. Caso San Nicolás Totolapan. Estudios Sociales, 20(40), 36-48.

Balam S. C. (2007). Manual para la planeación de un turismo responsable en áreas naturales comunales y ejidales. México. D. F.: Fondo Mexicano para la Conservación de la Naturaleza.

Burrel, G y Morgan, G. (1979). Sociological Paradigms and Organizational Analysis. Elements of de Sociology of Corporate Life. Great Britain: Heinemann Educational Books. 
Castellanos, I., García, N. E., y Cano, Z. (2017). Procesos físicos del suelo en la reserva ecológica del Pedregal de San Ángel de Ciudad Universitaria: atributos para su conservación. Terra Latinoamericana, 35(1), 51-64. https://doi. org/10.28940/terra.v35i1.241

Coraggio, J. L. (2011). Economía social y solidaria. El trabajo antes que el capital. Quito: Abya Yala.

Correa, M. E., Flynn, S. y Amit, A. (2004). Responsabilidad social corporativa en América Latina: una visión empresarial. Serie medio ambiente y desarrollo. División de desarrollo sostenible y Asentamientos Humanos. Santiago de Chile: CEPAL.

Corenader. (2010). Programa Turismo en la Naturaleza. México. Fotocopia.

Chirinos, M. E., Fernández, L. y Sánchez, G. (2013). Responsabilidad Empresarial o Empresa Socialmente Responsable. Razón y Palabra, 16(81), 1-17.

Da Ros, G. S. (2007). Economía Solidaria: aspectos teóricos y experiencias, Unircoop, 5(1), 9-27.

De la Rosa, M. E. (coord.) (2016). Practicas y tendencias del desarrollo sustentables y la responsabilidad social. Sonora: Jorale, UniSon.

Epstein, M. (2009). Sostenibilidad empresarial. Bogotá, D.C.: Ecoe.

Estados Unidos Mexicanos. Congreso de la Unión. (2016). Decreto por el que se declaran reformadas y derogadas diversas disposiciones de la Constitución Política de los Estados Unidos Mexicanos, en materia de la reforma política de la Ciudad de México. Diario Oficial de la Federación: 29/01/2016. Obtenido de http://www.dof.gob.mx/nota_detalle.php?codigo $=5424043 \&$ fecha $=29 / 01 / 2016$

Estados Unidos Mexicanos. Gobierno de la CDMX. (2018). Programa Turismo Alternativo y Patrimonial. [Online]. Recuperado de https:/tramites.cdmx.gob.mx/inicio/ $\mathrm{ts} / 851 / 0$ 
Estados Unidos Mexicanos. Gobierno del Distrito Federal. (1 de agosto de 2000). Decreto de Programa General de Ordenamiento Ecológico del Distrito federal. Gaceta Oficial del Distrito Federal, Décima época(139), 1-89. Recuperado http://www.cms.sedema.cdmx.gob.mx/storage/app/ uploads/public/595/138/60b/59513860b02f7865727855. pdf

Estados Unidos Mexicanos. Procuraduria Federal de Proteccion al Ambiente. (2019). Programa nacional de auditoría ambiental. [Industria Limpia]. Disponible en https://www. gob.mx/profepa/acciones-y-programas/programa-nacional-de-auditoria-ambiental-56432

Estados Unidos Mexicanos. Secretraria del Medio Ambiente. (2017). Reglas de operación del programa social Desarrollo rural y sustentable Tlalpan 2017 Ciudad de México. Gaceta Oficial de la Ciudad de México. Recuperado de http://www.cms.sedema.cdmx.gob.mx

Estados Unidos Mexicanos. Secretraria del Medio Ambiente. (2014). Programa Sectorial Ambiental y de Sustentabilidad 2013-2018-CDMX. Ciudad de México. Gaceta oficial de la Ciudad de México. Recuperado de http://www.cms. sedema.cdmx.gob.mx

Estados Unidos Mexicanos. Secretaría de Medio Ambiente y Recursos Naturales. (2013). Requisitos y especificaciones de sustentabilidad del ecoturismo. [Norma Mexicana NMXAA-133-SCFI-2013]. Recuperado de https://www.gob.mx/ semarnat/acciones-y-programas/nmx-133-ecoturismo

Estados Unidos Mexicanos. Secretaría de Turismo Federal (Sectur). (2017). Certificación de Calidad y Procesos. [Distintivo "M" Moderniza]. Recuperado de http://www.nl.gob.mx/ servicios/certificacion-de-calidad-y-procesos-distintivo-mmoderniza

Friedman, M. (septiembre 13, 1970). The social responsibility of business is to increase its profits. The New York Times, $12,32-33$ 
Guerra, P. (2013). Las legislaciones sobre economía social y solidaria en América Latina entre la autogestión y la visión sectorial. México. Revista de la Facultad de Derecho, 33(1), 73-94.

Guerra, P. (2011). ¿Cómo denominar a las experiencias económicas solidarias basadas en el trabajo? Diálogo entre académicos latinoamericanos acerca de la polémica conceptual. Otra Economía, 1(1), 21-27.

Guerra, P. (2010). La Economía Solidaria en Latinoamérica. Papeles de relaciones ecosociales y cambio global, 110(1), $67-76$.

Guridi, L. y Pérez, J. C. (2014). La dimensión económica del Desarrollo Humano Local: La economía social y solidaria. Bilbao: UPV/EHU.

International Organization for Standardization. (1996). Sistema de Gestión Ambiental (SGA). [ISO 14000]. Disponible en https://www.iso.org/home.html

International Organization for Standardization. (1987). Gestión para el éxito sostenido de una organización. Enfoque de gestión de la calidad. [ISO 9000]. Disponible en https:// www.iso.org/home.html

Laville, J. L. y García, J. (2009). Crisis capitalista y Economía Solidaria. Barcelona: Icaria

Licandro, O., Ramírez, A., Alvarado-Peña, L, Vega, L. y Correa, P. (2019). Implementation of the ISO 26000 Guidelines on Active Participation and Community Development. Social Sciences, 8(9), 263. https://doi.org/10.3390/socsci8090263

Lozano, J. (2011). Que es la ética de la empresa. Madrid: Proteus. ONU. (2015). Transformar nuestro mundo: la Agenda 2030 para el Desarrollo Sostenible. [A/70/L.1]. Online. Recuperado de https://undocs.org/A/70/L.1

Palomino, B. y López, G. (2011). Acercamiento a la responsabilidad social empresarial de las microempresas de ecoturismo indígena en México. Tourism \& Management Studies, 1(1), 982-989. 
Palomino, B. y López, G. (2015). Ecoturismo y conservación del patrimonio natural y sociocultural de Ciudad de México. Cuadernos de RSO, 3(2). pp. 101-112

Pérez, J. C., Etxezarreta, E. y Guridi, L. (2009). Economía Social, Empresa Social y Economía Solidaria: diferentes conceptos para un mismo debate. Papeles de Economía Solidaria, (1), 1-41.

Pérez, J. C. (2014). Debates conceptuales y aspectos organizativos de la Economía Solidaria: el caso de REAS Euskadi. [Tesis Doctoral]. Universidad del Pais Vasco, Vitoria-Gasteiz. Recuperado de http://pdf2.hegoa.efaber.net/entry/ content/1642/TESIS_J.C_Pz_de_Mendiguren.pdf

Unión Europea. Comisión de las Comunidades Europeas. (2001). Libro Verde. [COM(2001) 3]. Online. Recuperado http://www.europarl.europa.eu/meetdocs/committees/ deve/20020122/com(2001)366_es.pdf

UNWTO. (2014). Global Report on Adventure Tourism. Madrid: AM Reports. Recuperado de https://skift.com/wp-content/uploads/2014/11/unwto-global-report-on-adventuretourism.pdf

Wilson, M. (2003). Independent Assurance on Corporate Sustainability Reports: An Overview of Current Approaches. Vancouver: Price Waterhouse

Zamagni, S. (2014). La economía civil en la perspectiva de la doctrina social de la Iglesia. Revista de fomento Social, 69 (273-274), 65-84. 
El presente artículo es producto de la investigación: Organización comunitaria como factor de éxito en empresas de turismo naturaleza, apoyada por la Secretaría de Investigación y Posgrado del Instituto Politécnico Nacional de México.

Bertha Palomino Villavicencio tiene un doctorado en Educación y Maestría en Ciencias en Medio Ambiente y Desarrollo Integrado con Licenciatura en Medicina. Investigador de las Líneas de investigación: Sustentabilidad, empresa y creación de valor y Turismo alternativo, medio ambiente y desarrollo sustentable. Maestría en Ciencias de Administración de Negocios de la Escuela Superior de Comercio y Administración plantel Tepepan del Instituto Politécnico Nacional (México). https://orcid.org/0000-0003-056-6824

Gustavo López Pardo tiene un doctorado en Sociología y Maestría en Sociología con Licenciatura en Sociología. Investigador de la Línea de investigación: Turismo y medio ambiente, capital social y desarrollo comunitario perteneciente a la Unidad de investigación en Economía y Medio Ambiente del Instituto de Investigaciones Económicas de la Universidad Nacional Autónoma de México (México). https://orcid.org/0000-0002-5984-916 